\title{
Viability of the Alaskan Breeding Population of Steller's Eiders
}

Open-File Report 2016-1084 



\section{Viability of the Alaskan Breeding Population of Steller's Eiders}

By Kylee Dunham and James B. Grand

Open-File Report 2016-1084 


\section{U.S. Department of the Interior SALLY JEWELL, Secretary}

\section{U.S. Geological Survey Suzette M. Kimball, Director}

\section{U.S. Geological Survey, Reston, Virginia: 2016}

For more information on the USGS - the Federal source for science about the Earth, its natural and living resources, natural hazards, and the environment—visit http://www.usgs.gov or call 1-888-ASK-USGS.

For an overview of USGS information products, including maps, imagery, and publications, visit http://store.usgs.gov.

Any use of trade, firm, or product names is for descriptive purposes only and does not imply endorsement by the U.S. Government.

Although this information product, for the most part, is in the public domain, it also may contain copyrighted materials as noted in the text. Permission to reproduce copyrighted items must be secured from the copyright owner.

Suggested citation:

Dunham, Kylee, and Grand, J.B., 2016, Viability of the Alaskan breeding population of Steller's eiders: U.S. Geological Survey Open-File Report 2016-1084, 8 p., http://dx.doi.org/10.3133/ofr20161084.

ISSN 2331-1258 (online) 


\section{Acknowledgments}

The authors would like to thank the U.S. Fish and Wildlife Service, Alaska Region - Fairbanks

Field Office and Migratory Bird Management, Alabama Cooperative Fish and Wildlife Research Unit (ALCFWRU), and Auburn University for project funding. More specifically, we thank Ted

Swem, Kate Martin, Julian Fischer, Tuula Hollmen, and David Safine for their assistance in procuring funding.

Additionally, we would like to thank James D. Nichols, Abby Powell, and Mevin Hooten of the U.S. Geological Survey for their helpful comments on this manuscript. 



\section{Contents}

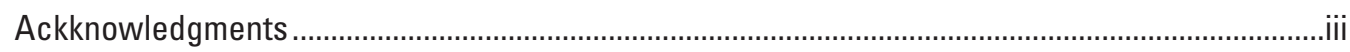

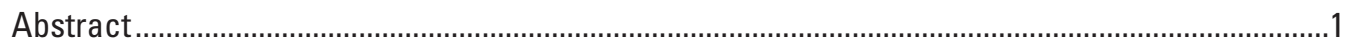

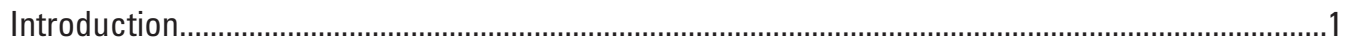

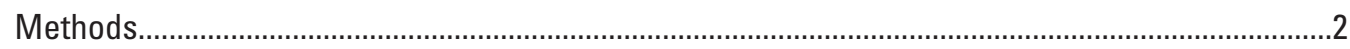

Population Models and Parameterization ..................................................................................2

Closed Population Model ...............................................................................................

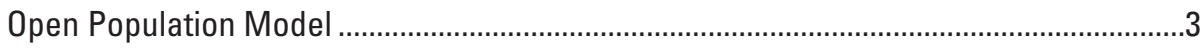

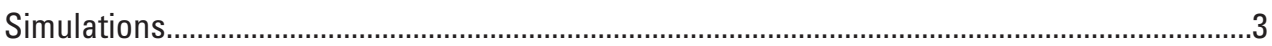

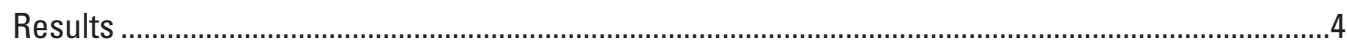

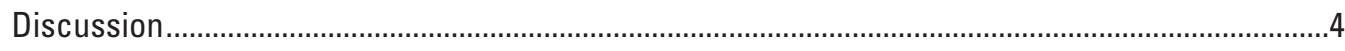

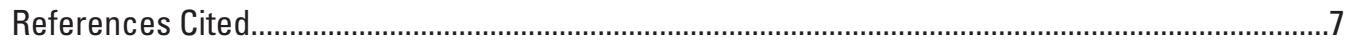

\section{Figures}

1-4. Graphs showing-

1. Mean population size projections with 95 percent credible intervals for the closed population model of Alaskan breeding Steller's eiders............................................4

2. Mean population size projections with 95 percent credible intervals for the open population model of Alaskan breeding Steller's eiders............................................5

3. Prior distribution for year 1 and posterior distributions of population size from projections for years 50 and 100 from the open model of population process for Alaskan breeding Steller's eiders.

\section{Abbreviations}

ACP Arctic Coastal Plain

ESA Endangered Species Act

PVA population viability analysis 


\title{
Viability of the Alaskan Breeding Population of Steller's Eiders
}

\author{
By Kylee Dunham ${ }^{1}$ and James B. Grand ${ }^{2}$
}

\section{Abstract}

The U.S. Fish and Wildlife Service is tasked with setting objective and measurable criteria for delisting species or populations listed under the Endangered Species Act. Determining the acceptable threshold for extinction risk for any species or population is a challenging task, particularly when facing marked uncertainty. The Alaskan breeding population of Steller's eiders (Polysticta stelleri) was listed as threatened under the Endangered Species Act in 1997 because of a perceived decline in abundance throughout their nesting range and geographic isolation from the Russian breeding population. Previous genetic studies and modeling efforts, however, suggest that there may be dispersal from the Russian breeding population. Additionally, evidence exists of population level nonbreeding events. Research was conducted to estimate population viability of the Alaskan breeding population of Steller's eiders, using both an open and closed model of population process for this threatened population. Projections under a closed population model suggest this population has a 100 percent probability of extinction within 42 years. Projections under an open population model suggest that with immigration there is no probability of permanent extinction. Because of random immigration process and nonbreeding behavior, however, it is likely that this population will continue to be present in low and highly variable numbers on the breeding grounds in Alaska. Monitoring the winter population, which includes both Russian and Alaskan breeding birds, may offer a more comprehensive indication of population viability.

\section{Introduction}

The U.S. Fish and Wildlife Service is tasked with setting objective and measurable criteria for delisting species or populations listed under the Endangered Species Act. These criteria are described within a recovery plan, which serves as a guide for the management and recovery of threatened and

\footnotetext{
${ }^{1}$ Auburn University.

${ }^{2}$ U.S. Geological Survey.
}

endangered species. Common recovery criteria include assessing the imperiled population in terms of extinction risk and setting extinction risk thresholds that, once reached, indicate when the population can be delisted. Determining the acceptable threshold for extinction risk for any species or population is a challenging task, particularly when uncertainty surrounding the demography of populations is great. The task becomes increasingly difficult because imperiled species typically are rare or uncommon at the time of listing, and generally little is known about their biological or population processes. Assessing a population's risk of extinction requires indepth knowledge of the population's processes and dynamics. If applicable, these processes may include interactions with nearby populations of the same species. Considering the potential influence of exchanges between two or more populations may be imperative to determining persistence or extinction risk.

Species or populations are listed under the Endangered Species Act (ESA) because of an increased risk of extinction. The Alaskan breeding population of Steller's eiders (Polysticta stelleri) was listed as threatened under the ESA in 1997 because of a perceived decline in abundance throughout their nesting range and geographic isolation from the Russian breeding population (U.S. Fish and Wildlife Service, 1997; Pearce and others, 2005). The Alaskan breeding population is the smallest of three geographically distinct breeding populations of Steller's eiders: the Russian-Atlantic population, the Russian-Pacific population, and the Alaskan population (Fredrickson, 2001; U.S. Fish and Wildlife Service, 2002; Pearce and others 2005).

A recovery plan was drafted for the Alaskan breeding population of Steller's eiders in 2002, defining the listed "population” as any Steller's eiders that breed in Alaska, and the term "subpopulation” to mean a group of Steller's eiders that form a geographic subunit of the Alaska breeding population (U.S. Fish and Wildlife Service, 2002). According to the recovery plan, two subpopulations of Steller's eiders were defined and denoted as the northern and western Alaskan subpopulations (U.S. Fish and Wildlife Service, 2002). One of the primary reasons for listing the Alaskan breeding population was the near extirpation of the western subpopulation along the Yukon-Kuskokwim Delta where the Yukon and Kuskokwim Rivers empty into the Bering Sea (U.S. Fish and Wildlife 
Service, 2002). Since the mid-1970s, only seven Steller's eider nests have been found on the Yukon-Kuskokwim Delta, with no indication of an established population (Kertell, 1991; Herzog, 1999; U.S. Fish and Wildlife Service, 2002). The recovery criterion for delisting and reclassifying the species from threatened to endangered includes considerations of the viability of both subpopulations (U.S. Fish and Wildlife Service, 2002). However, the influence of the western subpopulation on overall population viability cannot be considered owing to the lack of evidence of breeding in the region. Therefore, the viability of the northern subpopulation of Alaskan breeding Steller's eiders was assessed based the criteria from the recovery plan using aerial survey data provided by U.S. Fish and Wildlife Service (U.S. Fish and Wildlife Service, 2002).

Population viability analysis (PVA) is a tool commonly used to evaluate population persistence and estimate extinction risk (Shaffer, 1990; Boyce, 1992; Goodman, 2002; Morris and Doak, 2002; Robinson and others, 2014). Additionally, metapopulation viability analyses assess systems that are composed of interacting local populations that are open to immigration and emigration events. Metapopulation viability analyses account for movement among these local populations and the effect on dynamics. Most importantly, this movement allows for the possibility of recolonization following a local extinction (Levins, 1974; Hanski and Simberloff, 1997). Metapopulations can exhibit source-sink dynamics, in which there are local populations with births that outnumber deaths (source populations) and local populations with deaths that outnumber births (sink populations) (Hanski and Simberloff, 1997). These dynamics have critical implications for the assessment of local population viability and, therefore, conservation and management of local populations within a metapopulation. Population and metapopulation viability analyses are used to estimate the future state of the population(s) and quantify the probability of persistence or extinction (Goodman, 2002; Morris and Doak, 2002).

The Alaskan breeding population of Steller's eiders primarily nest on the Arctic Coastal Plain (ACP) along the northern coast of Alaska. Annual aerial surveys from 1989 to 2013 indicated that Steller's eiders were present in low and highly variable numbers, with multiple years in which zero birds were counted (Kertell, 1991; Pearce and others, 2005; Stehn and Platte, 2009; Stehn and others, 2013). Using the aerial survey dataset in previous work, we sought to develop and evaluate competing models of population process to determine the most likely process model for the Alaskan breeding population (Dunham and Grand, 2016). Results indicated that the Alaskan breeding population is likely open to immigration from the nearby Russian-Pacific breeding population and experiences population level nonbreeding events (Dunham and Grand, 2016). The dispersal of individuals from the RussianPacific breeding population to the Alaskan breeding population will likely have profound consequences for assessing the viability of the listed population. Additionally, the years in which zero birds are present on the breeding grounds present further challenges regarding estimating extinction risk. Typically, this phenomenon would qualify as a local extinction event followed by recolonization of the breeding area. However, it is believed to be representative of periodic nonbreeding behavior, a strategy employed by many long-lived species, including eiders (Coulson, 1984; Quakenbush and others, 1995; Solovieva, 1999; Obritschkewitsch and others, 2001; Quakenbush and others, 2004; Coulson, 2010; Safine, 2013).

Although our previous work strongly supports that the Steller's eider population is open to immigration and nonbreeding events, alternative hypotheses suggest that this is a closed population. Therefore, we aimed to estimate population viability of the threatened, Alaskan breeding population of Steller's eiders by using open and closed models of population process.

\section{Methods}

\section{Population Models and Parameterization}

In previous work, we developed and evaluated multiple models of population process and estimated key demographic parameters of the Alaskan breeding population (Dunham and Grand, 2016). We fit these models to annual aerial survey data collected from the ACP of Alaska to determine which process model(s) best fit the data and estimated the key demographic parameters associated with each model. The best fit process model included population level nonbreeding and timevarying immigration in addition to survival and fertility of the two sexes and the juvenile and adult age classes (Dunham and Grand, 2016). It has long been assumed that this breeding population is closed; however, the likelihood of population closure has never been formally evaluated. To address previous notions that this population is closed to immigration from the larger Russian-Pacific breeding population, we also assessed population viability under assumptions of population closure. Although our previous work suggests that this breeding population is open to immigration, we chose to evaluate population viability under both process models for transparency.

\section{Closed Population Model}

We developed a two-stage, two-sex matrix population model corresponding to a pre-breeding census for the Alaskan breeding population of Steller's eiders. We used the resulting posterior distributions for each vital rate from our previous Bayesian analysis to construct and parameterize each projection matrix model (Dunham and Grand, 2016). Using the posterior probability distributions from our previous analysis allowed us to incorporate the most accurate information available while accounting for multiple sources of uncertainty. The model for the dynamics of the closed population was defined as 


$$
\left[\begin{array}{l}
N_{j f} \\
N_{a f} \\
N_{j m} \\
N_{a m}
\end{array}\right]_{t}=\left[\begin{array}{cccc}
0 & f_{f} & 0 & 0 \\
S_{j f} & S_{a f} & 0 & 0 \\
0 & f_{m} & 0 & 0 \\
0 & 0 & S_{j m} & S_{a m}
\end{array}\right]_{t-1}\left[\begin{array}{c}
N_{j f} \\
N_{a f} \\
N_{j m} \\
N_{a m}
\end{array}\right]_{t-1}
$$

where $N$ is the number of individuals in each age-sex class, $S$ is age-sex specific survival, and $f$ is sex-specific fertility. The first stage represents birds that were 1 year old and reproductively immature, and survival $\left(S_{j f, j m}\right)$ was set equal between the sexes. Juvenile survival was chosen from a beta distribution with a mean of 0.748 and a standard deviation of 0.011 (Dunham and Grand, 2016). Adult survival was the annual survival rate ( $S_{a f, a m}$ ) of birds 2 years old and older, and we assumed all adult birds of the same sex experienced a similar survival rate. Adult male survival was estimated to be high, chosen from a beta distribution with a mean of 0.81 and a standard deviation of 0.009 , as estimated in previous analyses (Dunham and Grand, 2016). Adult female survival is characteristically lower than male survival and more variable because of the increased energetic costs and increased predation risk associated with nesting (Williams, 1966; Stearns, 1976; Erikstad and others, 1998; Flint and others, 2000; Ghalambor and Martin, 2001). Adult female survival was taken from a beta distribution with a mean of 0.754 and a standard deviation of 0.015 (Dunham and Grand, 2016). Fertility rates for the Alaskan breeding population are exceptionally low. Although low fertility rates are typical of a long-lived sea duck, results from our previous analysis indicate that the rates are lower than previously expected. Fertility rates were set equal between the sexes and drawn from a stretched beta distribution with a mean of 0.0062 and a standard deviation of 0.00015 (Dunham and Grand, 2016).

\section{Open Population Model}

The open population model used the same general framework as the closed population model, with two additional parameters. The open population model included an additional vector $I_{t}$, to represent immigration, and fertility was set dependent on a binomial random variable, breeding probability. The open population dynamics model was as follows:

$$
\left[\begin{array}{l}
N_{j f} \\
N_{a f} \\
N_{j m} \\
N_{a m}
\end{array}\right]_{t}=\left[\begin{array}{cccc}
0 & f_{f} & 0 & 0 \\
S_{j f} & S_{a f} & 0 & 0 \\
0 & f_{m} & 0 & 0 \\
0 & 0 & S_{j m} & S_{a m}
\end{array}\right]_{t-1}\left[\begin{array}{c}
N_{j f} \\
N_{a f} \\
N_{j m} \\
N_{a m}
\end{array}\right]_{t-1}+\left[\begin{array}{c}
0 \\
I_{a f} \\
0 \\
I_{a m}
\end{array}\right]_{t}
$$

where $I_{t}$ includes the number of adult female ( $a f$ ) and adult male (am) immigrants estimated at the current time step, $t$. This population is strictly made up of breeding birds and more specifically breeding pairs, and therefore the number of immigrants simulated in any time step is divided equally between the sexes. Additionally, because this is representative of the breeding population and juveniles do not breed, we did not allow for juvenile immigrants in this model. Immigration, $I_{t}$, was treated as a random effect, or time-varying parameter. At each time step, the number of immigrants was simulated from a zero-inflated Uniform distribution, which we parameterized as

$$
\left\{\begin{array}{c}
0, \text { with probability } \sim(0.2) \\
\text { Uniform }(1,1500) \text { with probability }(1 \quad \text { probability }(0))
\end{array}\right.
$$

Our previous study resulted in posterior distributions for immigration at each time step (Dunham and Grand, 2016). Considering the posterior distributions from this work, we chose to use a Uniform distribution to capture the uncertainty that exists surrounding the drivers of immigration. An additional constraint on immigration was set by the relation with the nonbreeding years. In our previous modeling effort, years in which zero birds were detected were representative of years that the population did not breed and did not experience any immigration (Dunham and Grand, 2016). The annual surveys and our model indicated that there were 5 nonbreeding years out of the 25 years of annual survey data (Dunham and Grand, 2016). Therefore, the probability of a nonbreeding year was roughly 20 percent. Furthermore, the 25 years of aerial survey data did not include any consecutive nonbreeding events; therefore, we never allowed nonbreeding years to occur consecutively in this model. Fertility, $f_{f, m}$, is defined as the number of offspring recruited to the juvenile (1-year-old) age class per female annually and is dependent on the nonbreeding probability, which is parameterized as a random binomially distributed variable that returns a 0 to represent nonbreeding years and 1 for breeding years. Therefore, in breeding years, fertility was drawn from a beta distribution with a mean of 0.0062 and a standard deviation of 0.00015 , and in nonbreeding years, fertility was set equal to zero. Survival rates were simulated from the same distributions described for the closed population model.

\section{Simulations}

Both models of population dynamics were projected to 100 years using 5,000 iterations. The closed population model was initialized with a population size ( $\left.N_{1}\right)$ chosen from the following distribution:

$$
N_{1} \sim \operatorname{Poisson}(\lambda)
$$

where $\lambda=1,000$; this distribution was reflective of the posterior distribution of population size from our previous analysis (Dunham and Grand, 2016). The initial population size for the open population model was estimated by adding $N_{1}$ and $I_{1}$. The initial age distribution was distributed according to 
the mean age distribution of the posterior results from our previous analysis, with additional variation to reflect our uncertainty in this estimate. The age distribution included the proportion of each stage and sex class in the population.

We were interested in comparing the model projections to the metrics defined in the recovery plan (U.S. Fish and Wildlife Service, 2002); however, some metrics are not presently applicable, according to the current wording of the recovery plan. For this reason, we are only interested in the metrics that are currently applicable to this population. Therefore, we report the probability of extinction and the mean time to extinction for the closed model projections and the probability of extinction for the open model projections. Extinction was defined as the population size being zero individuals and mean time to extinction was the year in which the mean population size was equal to zero.

\section{Results}

The closed model resulted in a 100 percent probability of extinction within 42 years, and the mean time to extinction was 35 years (fig. 1). The open population model resulted in 19.28 percent of the iterations reaching the extinction threshold of zero individuals and 0.006 percent of the iterations reaching extinction at some point in the 100 years of projection. Because this population occurs in low and highly variable numbers on the breeding grounds, there is still some expectation that this local population will experience temporary decreases in population size. However, because of frequent immigration, there is no probability of long-term or permanent quasi-extinction or extinction for this breeding population. Owing to the rescue effect of immigration, it is not possible to measure a time to quasi-extinction or time to extinction, because there was no time in which all iterations reached either threshold (figs. 2, 3).

\section{Discussion}

Without the reintroduction or recolonization of the Yukon-Kuskokwim Delta by the western subpopulation of Alaskan Steller's eiders or the designation of the subpopulations as distinct vertebrate population segments, the recovery criteria as listed in the recovery plan cannot be met (U.S. Fish and Wildlife Service, 2002). However, we sought to assess the viability of the northern subpopulation of Alaskan breeding Steller's eiders by using two models. The results of the closed population projections suggest that the population would rapidly decline and become extinct within 42 years and would therefore qualify to be reclassified as endangered, according to the current recovery criteria (fig. 1). Although our previous models suggest a closed model is an unlikely representation of this population process, we included this model for comparison and to address alternative hypotheses regarding population closure. Additionally, previous studies of the geographically distinct breeding populations (Russian-Atlantic, RussianPacific, and Alaskan) suggest there is no significant genetic

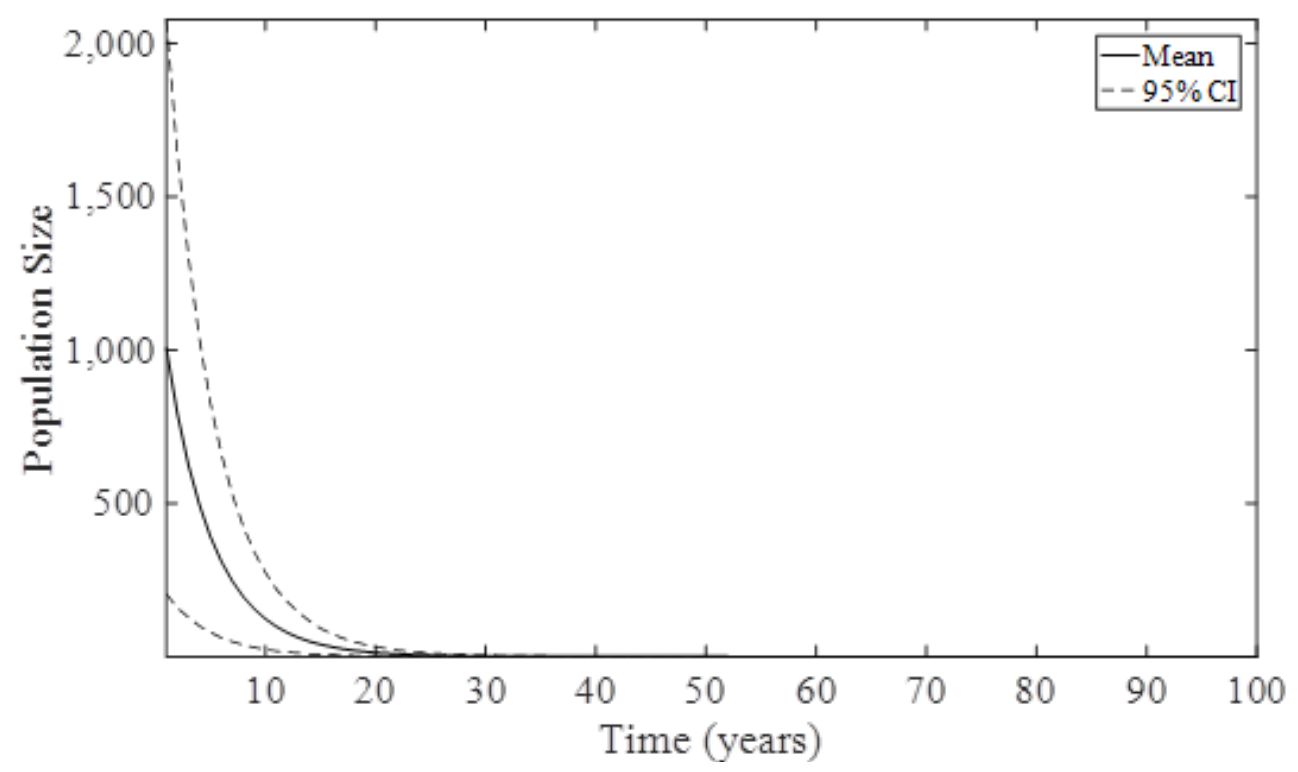

Figure 1. Mean population size projections with 95 percent credible intervals for the closed population model of Alaskan breeding Steller's eiders (Polysticta stelleri). 


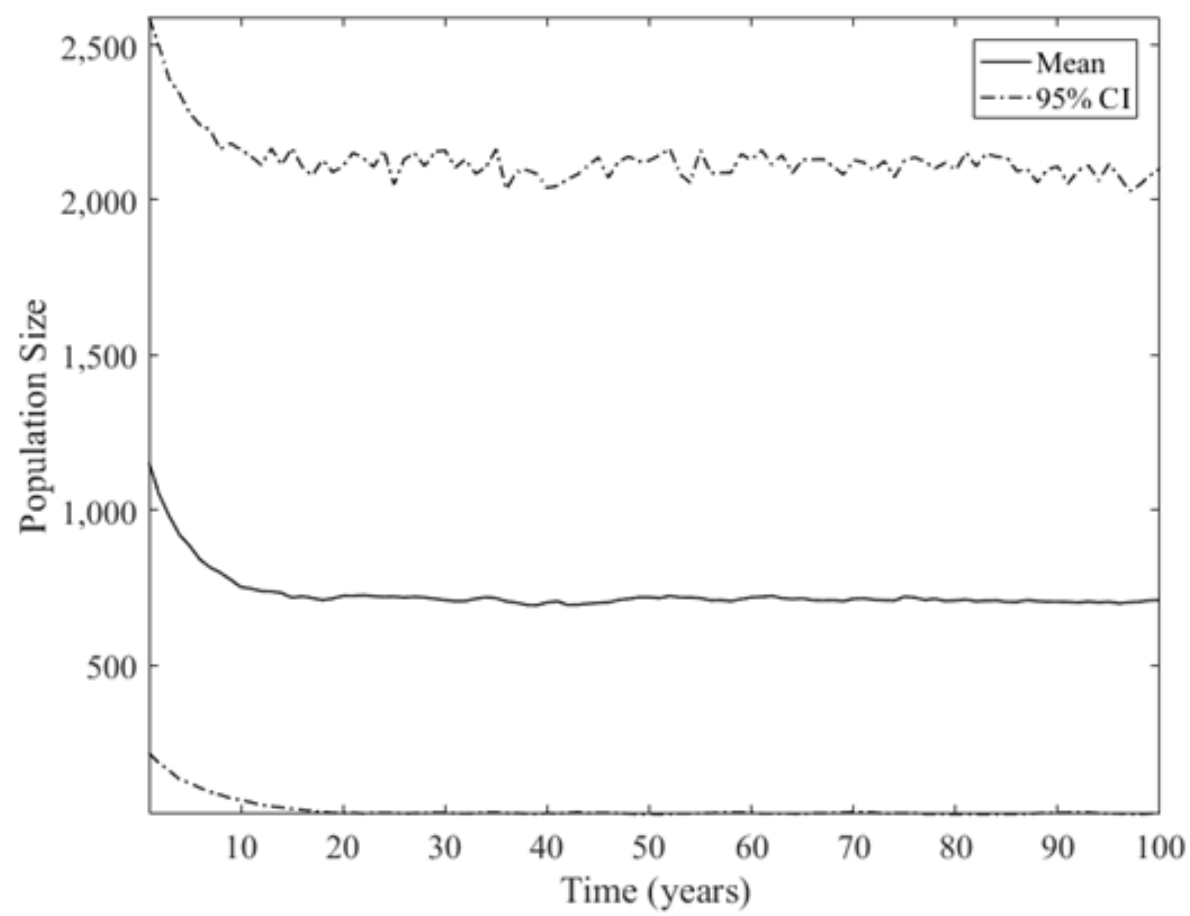

Figure 2. Mean population size projections with 95 percent credible intervals for the open population model of Alaskan breeding Steller's eiders (Polysticta stelleri).
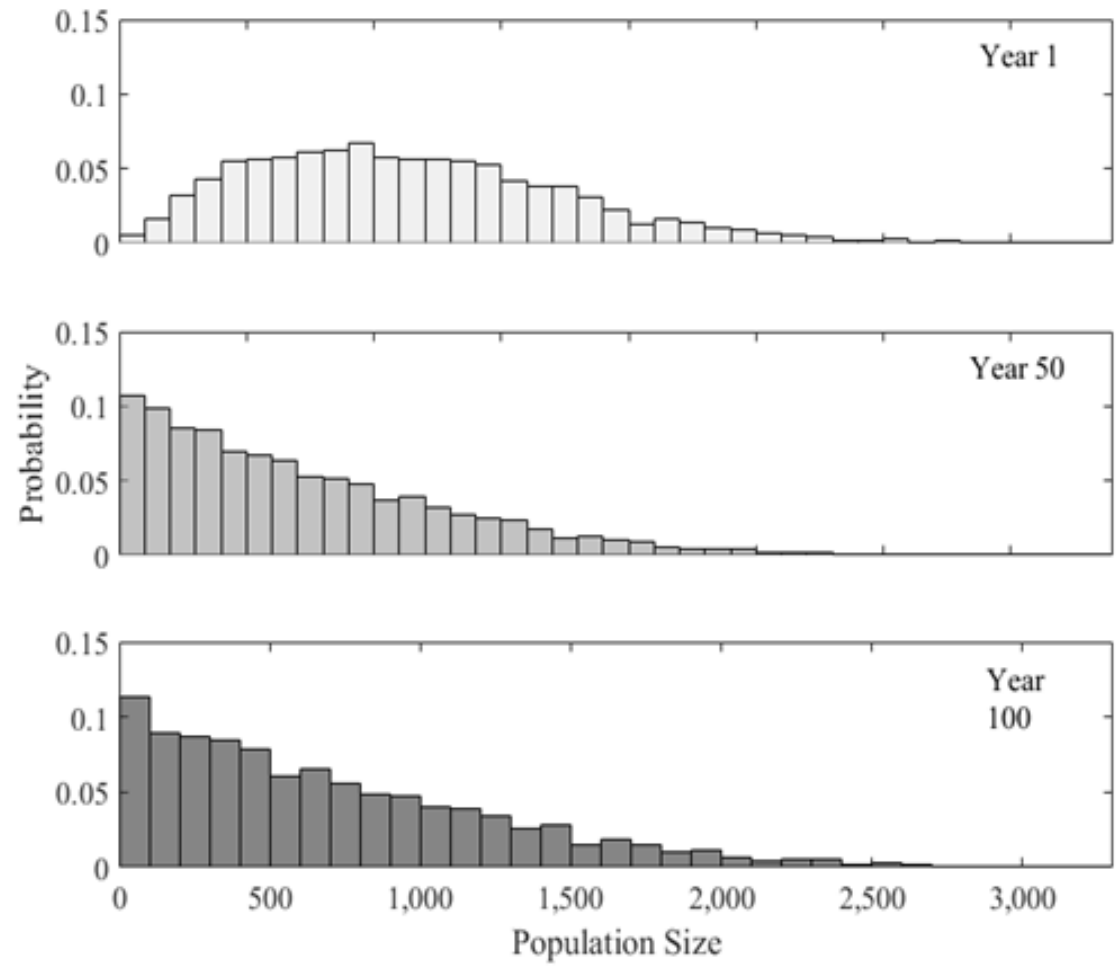

Figure 3. Prior distribution for year 1 and posterior distributions of population size from projections for years 50 and 100 from the open model of population process for Alaskan breeding Steller's eiders (Polysticta stelleri). Posterior distributions are skewed heavily toward zero, suggesting very small population sizes are highly likely. 
Viability of the Alaskan Breeding Population of Steller's Eiders

differentiation between the Alaskan and Russian-Pacific breeding populations (Pearce and others, 2005). The results of these studies illustrate that it is highly unlikely that this breeding population is closed because the productivity and survival rates do not support a self-sustaining population. This information is critical for the management and monitoring of this listed breeding population.

The Alaskan breeding population was listed due to perceived declines in abundance in their nesting and breeding range, specifically along the Yukon-Kuskokwim Delta (U.S. Fish and Wildlife Service, 2002). One of the primary objectives listed in the recovery plan was to gather more information on breeding population dynamics to assess population viability (U.S. Fish and Wildlife Service, 2002). Analysis of 25 years of aerial survey data indicated that this population had been rescued through immigration events and experienced intermittent breeding (Dunham and Grand, 2016). Given this updated understanding, we believe the model put forth in this research is the best available representation of population process and dynamics. The mean projected results from this model indicate that the Alaskan breeding population will likely remain relatively stable throughout the next 100 years, with no probability of permanent local extinction; however, this projection is dependent on immigration and, thus, the viability of the large Russian source population (fig. 1). The outcome of this study combined with our previous research suggests that immigration plays a critical role in the population dynamics and consequently the viability of the Alaskan breeding population of Steller's eiders (Dunham and Grand, 2016).

Our previous study highlighted the importance of immigration in accounting for the highly variable observed counts of the breeding population on the ACP (Dunham and Grand, 2016). Furthermore, the current study identifies the role of immigration as being vital to the viability of the Alaskan breeding population. The significant role of immigration may be representative of source-sink dynamics. In this case, the source population would be the Russian-Pacific breeding population, and the Alaskan breeding population would act as the sink. Öst and others (2016) found that immigration played a similar role in population dynamics of common eiders (Somateria mollissima) breeding in two different geographic locations in the Baltic Sea. After analyzing long-term individual-based data on eider breeding success and survival, Öst and others (2016) detected these dynamics because offspring production was not high enough to explain population growth during times of rapid increase. In addition, the breeding population that experienced low reproductive success and speculated immigration is located along the eastern range margin and not within the core breeding range (Öst and others, 2016). Although common eiders do exhibit strong breeding site fidelity, Öst and others (2016) believe natal dispersal could be a strong driver of the apparent source-sink dynamics. Similarly, our previous research indicated that the best model of population process allowed for birds to enter the population, but at that point they remained in the population to mimic breeding site fidelity (Dunham and Grand, 2016).
Furthermore, Steller's eiders are thought to prospect for breeding sites in the year previous to becoming sexually mature. Even though most eider species exhibit breeding site fidelity, this study indicates that immigration is an important mechanism in regulating Steller's eider population dynamics, and it is likely that natal dispersal plays a large part in providing immigrants to the Alaskan breeding population.

Mean population projections suggest a relatively stable population; however, it is probable that the northern subpopulation of Steller's eiders will continue to be present in low and highly variable numbers on the ACP breeding grounds (figs. 2, 3). Typically, local extinction would be defined as any time at which there were zero individuals in the designated geographic area. In the case of this breeding population, the probability of location extinction about 20 percent in any year (Dunham and Grand, 2016). However, there is no definition of local extinction for this breeding population in the recovery plan (U.S. Fish and Wildlife Service, 2002). Therefore, it may be important to reconsider what extinction metrics apply when estimating the viability of this highly variable population.

While results strongly support that this breeding population is open to immigration and experiences population level nonbreeding events, we do not know what factors directly influence these occurrences. Further research is needed to identify factors that drive these important biological processes. Previous studies have indicated that there may be a relation between breeding probability and density of lemmings, pomarine jaegers (Stercorarius pomarinus), and snowy owls (Bubo scandiacus) (Quakenbush and others, 2004). However, direct links of the effects of interspecies relations to breeding probability in Alaskan breeding Steller's eiders have not been established. Additional hypotheses for causes of intermittent breeding in eider species may be linked to environmental factors, including direct and indirect effects of climate and (or) oceanic regime shifts that alter food availability (Coulson 1984, 2010). If breeding of Steller's eiders is linked to species specific densities on the breeding grounds or by environmental factors that influence survival and (or) breeding probability, we may be able to better predict their effects on population viability in the future. However, it is likely that as long as there is an available pool of immigrants from the Russian-Pacific population, the Alaskan breeding population will persist.

Our results suggest that immigration is necessary to sustain the Alaskan breeding population of Steller's eiders. We demonstrated that the variable number of breeding birds and the viability of this breeding population are influenced by intermittent breeding and dispersal from the RussianPacific breeding population (Dunham and Grand, 2016). Although there is little information on the Russian-Pacific breeding population, we know that they share molting and wintering grounds in southwestern Alaska with the Alaskan breeding population (Dau and others, 2000; Flint and others, 2000; Larned, 2012; Frost and others, 2013; Martin and others, 2015). Additionally, previous studies found that both sexes showed high rates of fidelity to specific molting sites (Flint and others, 2000). This information provides a unique 
opportunity to monitor both breeding populations on the molting and wintering grounds, to gain a more comprehensive understanding of metapopulation dynamics. Analysis of aerial surveys conducted from 1992 to 2010 on the spring staging areas along the Bristol Bay coast of the Alaskan Peninsula indicate that the long-term trend is an exponential decline of 2.4 percent per year (Larned, 2012). This apparent decline of the number of staging birds warrants further research and monitoring as this may indicate whether the metapopulation is at risk of extinction, which could increase the probability of permanent extinction of the Alaskan breeding population.

Finally, one of the most challenging issues faced when managing this species has been estimating population size and trend because of the difficulty associated with detectability. Throughout their annual cycle the species is dispersed over large geographic extents and is difficult to detect with precision. At this point we do not have recent or precise data to inform detection probability for Steller's eiders on the aerial surveys on the ACP. Without understanding the detection process we cannot accurately estimate population size or trend. We incorporated a large amount of uncertainty in initial population size to reflect our uncertainty in this estimate. Furthermore, the annual aerial survey point count estimates are imprecise, leading to further uncertainty about population trend and size. With estimates of detection probability and better understanding of detection process, we could reduce the uncertainty for each annual estimate of population size and consequently reduce the uncertainty in predictions of population size and trend. Precisely estimating detection probability on the aerial breeding ground surveys and on any surveys conducted on the molting or wintering grounds will be critical to informing the management and conservation of this species.

\section{References Cited}

Boyce, M.S., 1992, Population viability analysis: Annual Review of Ecological Systems, v. 23, p. 481-506.

Coulson, J.C., 1984, The population dynamics of the eider duck Somateria mollissima and evidence of extensive nonbreeding by adult ducks: Ibis, v. 126, p. 525-543.

Coulson, J.C., 2010, A long-term study of the population dynamics of common eiders Somateria mollissima-Why do several parameters fluctuate markedly? Bird Study, v. 57, p. 1-18.

Dau, C.P., Flint, P.L., and Petersen, M.R., 2000, Distribution of recoveries of Steller's eiders banded on the lower Alaska Peninsula, Alaska: Journal of Field Ornithology, v. 74, no. 3, p. 541-548.
Dunham, Kylee, and Grand, J.B., 2016, Evaluating models of population process in a threatened population of Steller's eiders-A retrospective approach: U.S. Geological Survey Open-File Report 2016-1062, 14 p., accessed September 2016, at http://dx.doi.org/10.3133/ofr20161062.

Erikstad, K.E, Fauchald, P., Tveraa, T., and Steen, H., 1998. On the cost of reproduction in long-lived birds: the influence of environmental variability: Ecology v. 79, no. 5, p. 1781-1788.

Flint, P.L., Petersen, M.R., Dau, C.P., Hines, J.F., and Nichols, J.D., 2000, Annual survival and site fidelity of Steller's eiders molting along the Alaska Peninsula: Journal of Wildlife Management, v. 64, no. 1, p. 261-268.

Fredrickson, L.H., 2001, Steller's eider (Polysticta stelleri), in Poole, A., ed., The birds of North America-Online: Ithaca, Cornell Lab of Ornithology, accessed May 16, 2016, at http://bna.birds.cornell.edu/bna/species/571.

Frost, C.J., Hollman, T.E., and Reynolds, J.H., 2013, Trends in annual survival of Steller's eiders at Izembek Lagoon on the Alaska Peninsula, 1993-2006: Arctic, v. 66, no. 2, p. 173-178.

Ghalambor, C. K., and Martin., T.E., 2001. Fecundity-survival trade-offs and parental risk-taking in birds. Science, v. 292, no. 5516, p. 494-497.

Goodman, D., 2002, Predictive Bayesian population viability analysis-A logic for listing criteria, delisting criteria and recovery plans, in Beissinger, S.R., and McCullough, D.R., eds., Population viability analysis: Chicago, The University of Chicago Press, p. 447-469.

Hanski, I., and Simberloff, D., 1997, The metapopulation approach, its history, conceptual domain, and application to conservation, in Hanski, I.A., and Gilpin, M.E., eds., Metapopulation biology: San Diego, Calif., Academic Press, p. 5-26.

Herzog, M.P., 1999, Breeding of Steller's eiders, Polysticta stelleri, on the Yukon-Kuskokwim Delta, Alaska: Canadian Field-Naturalist, v. 113, no. 2, p. 306-308.

Kertell, K., 1991, Disappearance of the Steller's eider from the Yukon-Kuskokwim Delta, Alaska: Arctic, v. 44, no. 3, p. 177-187.

Larned, W.W., 2012, Steller's eider spring migration surveys, southwest Alaska, 2012: U.S. Fish and Wildlife Service, 25 p., accessed May 16, 2016, at http://www.fws.gov/ alaska/mbsp/mbm/waterfowl/surveys/pdf/swstrpt12.pdf. 
Levin, S.A., 1974, Dispersion and population interactions: The American Naturalist, v. 108, no. 960, p. 207-228.

Martin, P.D., Douglas, D.C., Obritschkewitsch, T., and Torrence, S., 2015, Distribution and movements of Alaskabreeding Steller's eiders in the nonbreeding period: Condor, v. 117, no. 3., p. 341-353.

Morris, W.F., and Doak, D.F., 2002, Quantitative conservation biology - Theory and practice of population viability analysis: Sunderland, Mass., Sinauer Associates, Inc., 480 p.

Obritschkewitsch, T., Martin, P.D., and Suydam, R.S., 2001, Breeding biology of Steller's eiders nesting near Barrow, Alaska, 1999-2000: Fairbanks Alaska, Ecological Services, U.S. Fish and Wildlife Service Technical Report NAES-TR-01-04.

Öst, M., Ramula, S., Lindén, A., Karell, P., and Kilpi, M., 2016, Small-scale spatial and temporal variation in the demographic processes underlying the large-scale decline of eiders in the Baltic Sea: Population Ecology, v. 58, no. 1, p. 121-133.

Pearce, J.M., Talbot, S.L., Petersen, M.R., and Rearick, J.R., 2005, Limited genetic differentiation among breeding, molting, and wintering groups of the threatened Steller's eiderThe role of historic and contemporary factors: Conservation Genetics, v. 6, p. 743-757.

Petersen, M.R., Bustnes, J.O., and Systad, G.H., 2006, Breeding and moulting locations and migration patterns of the Atlantic population of Steller's eiders Polysticta stelleri as determined from satellite telemetry: Journal of Avian Biology, v. 37, p. 58-68.

Quakenbush, L.T., Suydam, R.S., Fluetsch, K.M., and Donaldson, C.L., 1995, Breeding biology of Steller's eiders nesting near Barrow, Alaska, 1991-1994: Fairbanks Alaska, Ecological Services, U.S. Fish and Wildlife Service Technical Report NAES-TR-95-03.

Quakenbush, L.T., Suydam, R.S., Obritschkewitsch, T., and Deering, M., 2004, Breeding biology of Steller's eiders (Polysticta stelleri) near Barrow, Alaska, 1991-99: Arctic, v. 57, no. 2, p. 166-182.
Robinson, O.J., Lockwood, J.L., Stringham, O.C., and Fefferman, N.H., 2014, A novel tool for making policy recommendations based on PVA-Helping theory become practice: Conservation Letters, p. 190-198, accessed May 16, 2016, at http://dx.doi.org/10.1111/conl.12146.

Safine, D.E., 2013, Breeding ecology of Steller's and spectacled eiders nesting near Barrow, Alaska, 2012: Fairbanks, Alaska, Fairbanks Fish and Wildlife Field Office, Technical Report, 64 p.

Shaffer, M.L., 1990, Population viability analysis: Conservation Biology, v. 4, no. 1, p. 39-40.

Solovieva, D.V., 1999, Biology and bioenergetics of the Steller's eider (Polysticta stelleri): St. Petersburg, Russia, Russian Academy of Sciences, Zoological Institute, Ph.D. dissertation.

Sterms, S.C., 1976, Life-history tactics-A review of the ideas: Quarterly Review of Biology, v. 51, no. 1, p. 3-47.

Stehn, R.A., Larned, W.W., and Platte, R.M., 2013, Analysis of aerial survey indices monitoring waterbird populations of the Arctic Coastal Plain, 1986-2012: Anchorage and Soldotna, Alaska, U.S. Fish and Wildlife Service, Migratory Bird Management, 35 p.

Stehn, Robert, and Platte, Robert, 2009, Steller's eider distribution, abundance, and trend on the Arctic Coastal Plain, Alaska, 1989-2008: Anchorage, Alaska, U.S. Fish and Wildlife Service, Migratory Bird Management, 35 p.

U.S. Fish and Wildlife Service, 1997, Endangered and threatened wildlife and plants; threatened status for the Alaska breeding population of the Steller's eider: Federal Register, v. 62, no. 112, p. 31748-31757, accessed May 16, 2016, at https://www.gpo.gov/fdsys/pkg/FR-1997-06-11/ pdf/97-15244.pdf.

U.S. Fish and Wildlife Service, 2002, Steller's eider recovery plan: Fairbanks, Alaska, U.S. Fish and Wildlife Service, 27 p.

Williams, G.C., 1966, Natural selection, the costs of reproduction, and a refinement of Lack's principle: The American Naturalist, v. 100, no. 916, p. 687-690. 
Manuscript was approved on May 20, 2016.

Prepared by USGS Science Publishing Network, Lafayette and Reston Publishing Service Centers

For more information, contact:

Chief, Cooperative Research Units

U.S. Geological Survey

12201 Sunrise Valley Drive

Reston, VA 20192-0002

https://www.usgs.gov/science/mission-areas/ecosystems 
